\title{
A Comparative Study of the Experimental Results of Mechanical Tests of Composite Material Made of Polyester-Reinforced Fiber and Glass Powder
}

\author{
${ }^{1}$ Suha Hashim Ahmed, ${ }^{2}$ Ghaidaa Ibrahim Husain \\ ${ }^{1,2}$ University of Mosul, Mechanical Department, College of Engineering, Mosul, Iraq
}

\begin{abstract}
The research includes an experimental study for the manufacture of a polymeric (saturated polyester) compound material manufactured by the Turkish company (Poliya Composite Resins and Polymers, Inc.) and its type (Polipol3455), which is a thermally hardened polymers fortified with random sizes of glass powder and glass fibers in different weight proportions, And then studying the mechanical properties of the manufactured models, and these properties included compressive and tensile resistance and hardness resistance, where the mechanical properties of polyester resin were initially extracted before being reinforced with random Pyrex glass powder of random shapes and with different weight proportions of glass powder and glass fibers $10 \%, 20 \%$, $30 \%$ and a study of the effect of this on the properties, The results showed that the tensile strength, compressive strength and stiffness resistance of glass-strengthened powder increased by $10 \%$, and at this rate the composite material became strong. As for the decrease in tensile and compressive strength by $20 \%, 30 \%$ is due to the insufficient amount of polyester used in gluing glass powder, thus the bonding strength between the base material and the reinforcing material decreases, which leads to a decrease in the tensile and compressive strength, and the unsaturated polyester hardness values increase With the addition of glass at a rate of $10 \%$, but the increase is less solid, with the increase in the percentage of weight, the mechanical properties improve with the increase in the percentage of fibers on the contrary when the proportion of the glass powder increases. In industry, glass fiber reinforced composites are used more than powder glass reinforced compounds, due to their higher mechanical and physical properties.
\end{abstract}

Keywords: powder glass, fiber glass, CNC machine tensile test, compression test, hardness test.

\section{NTRODUCTION}

Compound materials are heterogeneous materials, and they consist of two different materials, or perhaps more, and are combined with each other, so that a substance with properties that are different from the properties of its constituent materials is obtained. Small-sized materials were also used to obtain high properties that could not be obtained using conventional materials. These materials usually consist of two components, the Reinforce and the Matrix.

The reinforced material used in this study is powder and fiberglass. Glass is defined as a product that is molten due to the solid state without crystallization. The reinforced materials are either metal materials or they may be ceramic materials and the base material is polyester which is a polymeric material and it is the most widely used and widespread due to its good mechanics and thermal properties. Thermoplastic resins are added to the group.

The glass has the property of brittleness, which prevents it from being used in the manufacture of mechanical parts. This brittleness is due to the excessive sensitivity of the glass to the defects and cracks that arise during manufacture. The glass consists of materials: sand (at 70\%), soda (at 15\%), limestone (at 10\%), and additional materials (at 5\%) [7].

Glass fibers are glass in the form of discontinuous fibers, and these fibers may be more accurate than human hair many times, and they are in appearance and texture like silk, as they do not burn, stretch, rust or fade, and the most important characteristic of glass fibers is that they are stable, small dimensions and low weight It has a great resistance to breakage but can be broken when folded. It is not absorbent to moisture and water. It endures high temperatures and is not affected by acids, but it is weak in resistance to alkaline materials, insulating heat and electricity.

\section{LITERATURE REVIEW}

Engineer Aseel Mahmoud Abdullah and others, (2011), [1] They manufactured a composite material with a polymeric basis (polyester), reinforced with cut fiber glass (E-glass) and other models of the material with a polymeric basis strengthened with glass fibers and alumina particles together and with three different weight fractions (3, 5, 7\% wt)). Mechanical tests were performed on samples such as shock, hardness, and bending tests. From the results, it was found that the mechanical properties improved with increasing weight 
fracture. The absorbed energy of the fracture gave the best results for the glass fiber reinforced samples and alumina particles compared to the glass fiber reinforced samples only with the same weights.

Dr. Mayssa Shash, (2015), [2] conducted an experimental study to manufacture a composite material based on polymeric (unsaturated polyester) reinforced with random glass fibers with different weight ratios, and then a study of the mechanical properties of manufactured models, to determine the effect of the proportion of glass fibers on the resistance to tensile and hardness Impact resistance, and this study has shown that the best results were for samples reinforced with glass fibers by $40 \%$, where the tensile strength of the material increased by about $70 \%$, and the hardness increased by $30 \%$, and the impact resistance increased by $43 \%$, this study also showed that the increase of fibers to $60 \%$ It led to a decrease in the clearly studied mechanical properties, due Until the amount of unsaturated polyester becomes insufficient to bind the fibers, which leads to a weakening of the bonding forces in the composite material.

Dr. Abbas Alewi Al-Jubouri, (2009), [3] studied the effect of the fiber reinforcement ratio on the mechanical properties of the compound material consisting of vinyl ester resin reinforced with two-way glass fibers (45-0) degrees. These properties included shock resistance, tensile strength, and compression resistance as the mechanical properties of the vinyl ester resin were extracted before being reinforced with fibers, then the resin was reinforced with different weight proportions of glass fibers $(20 \%, 40 \%, 60 \%)$ and a study of the effect of this on the mentioned properties.

Ali Hassan Resan, (2017) [4] he attended hybrid superposition materials consisting of a polymeric base material which is unsaturated polyester resins and fortified with different types of reinforcing materials (glass fibers, carbon fibers, Kevlar fibers) I used the manual molding method In preparing the samples used for testing. Mechanical tests included tensile and compression strength tests.

\section{PRACTICAL PART}

The practical part includes preparing the raw materials and how to prepare the model casting molds in addition to the mechanical tests that were performed on the composite material. Tensile inspection molds and hardness test molds were made of transparent acrylic material by a device (AKJ1390H laser cutting metal machine) as shown in Figure (1).

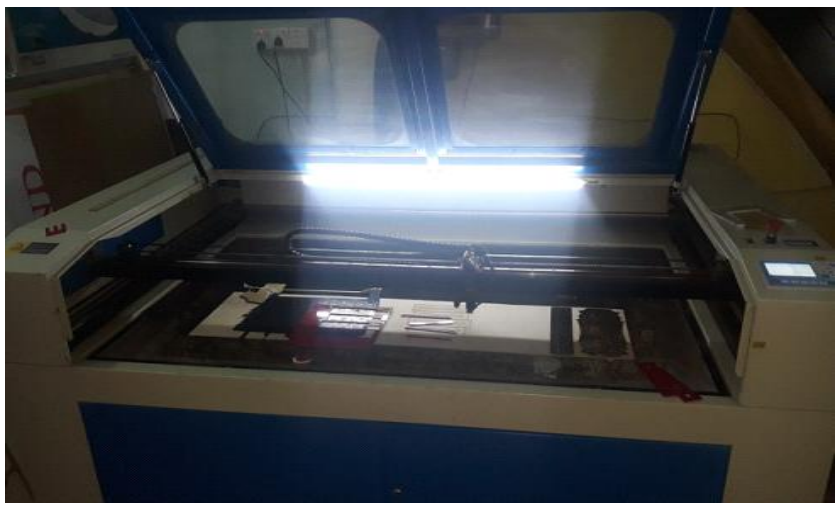

Figure 1: Shows the CNC machine

\subsection{Prepare the tests forms}

\subsubsection{Tensile strength testing models}

The tensile strength is a measure of the ability of the material to resist the static forces that attempt to pull the material and break it, the compound material begins to elongate linearly at the beginning in response to the voltage applied and with continuous loading a deviation occurs as a result of the base material reaching the yield point while the fibers continue to elongate and resist and when the base material is shattered The composite material fails completely [8], [9] and samples are prepared for tensile testing within ASTM stander D2990-77 standards, as shown in Figure (2) decree of the AUTO CAD program.
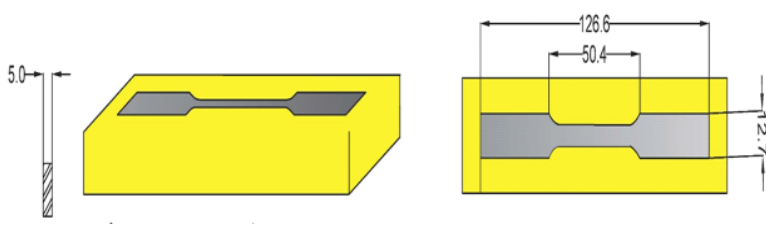

Figure 2: Shows the mold used for casting tensile strength test

\subsubsection{Compression resistance test models}

Compression resistance is an indication of the material's resistance against mechanical forces. The compression resistance of the base material and the composite material was measured using a general testing machine and was tested on samples in the form of a cube with a side length of $30 \mathrm{~mm}$. Figure No. (3) Showing the dimensions of the pressure resistance sample drawn in (AUTO CAD) program.

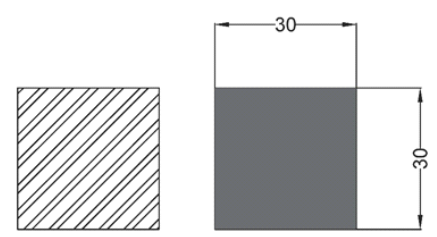

Figure 3: Shows the dimensions of the compression test template (mm) 
ISSN (online): 2581-3048

Volume 6, Issue 1, pp 132-137, January-2022 https://doi.org/10.47001/IRJIET/2022.601023

\subsubsection{Hardness resistance test models}

Hardness is a measure of the material's resistance to the plastic deformation that occurs in the material under external influence.

\subsubsection{Preparing samples for examination under a microscope}

Select the sample to be examined and then the smoothing process, where the excess is removed by a device equipped with polishing paper classified into four grades with continuous pumping of water and the smoothing process takes place from one stage to another where coarse paper is used and then smoothed (320-400-600-1000) until the purity of the paper measuring 1000 At each stage, the sample is rotated at a 90-degree angle and the purpose is to remove streaks and scratches left by the previous stage, and then the polishing process is polished on a rotary polishing device, which is similar to smoothing where a linen cloth is attached to the turntable and added to the turntable during the rotation of water with a solution and aluminum oxide After this the drying process, the sample dried in a stream of hot air using an electric dryer, and then the final stage scans the sample with an optical microscope.

As for the microscopic structure, samples were photographed after the preparation process and for all weight ratios of the added substance $(10 \%, 20 \%, 30 \%)$ and Figure No. (5) Shows the weights ratios of the random sizes of glass powder using a light microscope (VICKERS) with a magnifying power (X80).

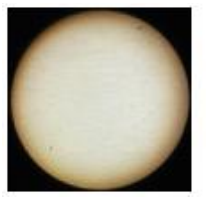

(a)

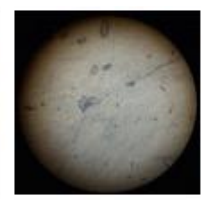

(b)

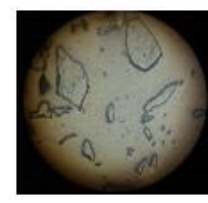

(c)

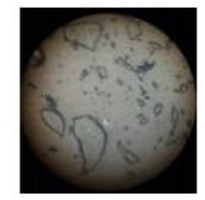

(d)
Figure 5: a-pure polyester b- $10 \%$ powder glass c- $20 \%$ powder glass d$30 \%$ powder glass

\section{RESULTS}

\subsection{Results of pressure test}

This resistance shows the tolerance of the material when exposed to a static compression load before it is broken, and a unit compression stress $(\mathrm{MPa})$ is usually measured and the high values indicate the large cohesion forces between the material particles. The results shown in Table No. 1 and Table No. (2) are the stress and strain values that result from compression force on the surface area of the samples of the polymeric compound made of pure and compound polyester at rates of $10 \%, 20 \%, 30 \%$ of glass powder where it was observed that the polymeric compound with a ratio of $10 \%$ is the best resistance to stress of (110) Mpa And with a higher strain value (0.073) also compared to other ratios and as we note that the sample gets failure upon stress $32.8 \mathrm{MPa}$, when strain value is $(0.11)$. This indicates that the sample with a ratio of $10 \%$ is more resistant to stress than the rest of the ratios, and that the increase in the proportion of glass at $20 \%$ and $30 \%$ gave the opposite results as compression decreased, and this is illustrated by Table No. (1) and Figure No. (6) clarifies the path of stress and strain of the proportions used.

Table 1: Shows the compression stress and strain values at the highest stress tolerance of the composite material for the weighted ratios

\begin{tabular}{|c|c|c|c|c|}
\hline & pure & $10 \%$ & $20 \%$ & $30 \%$ \\
\hline $\begin{array}{c}\text { Ultimate } \\
\text { stress(MPa) } \\
\text { strain }\end{array}$ & 104 & 110 & 89.33 & 85.88 \\
\hline
\end{tabular}

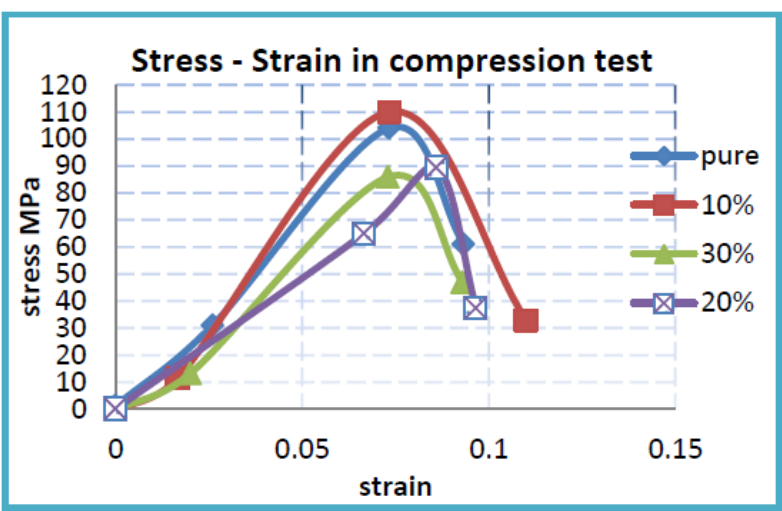

Figure 5: shows the stress and strain of the ratios of glass powder used in compression test

Table 2: Shows the results of stresses of the highest stress value of the composite material to the compression test of the ratios of fiber glass used

\begin{tabular}{|c|c|}
\hline $\begin{array}{c}\text { The percentage of fiber } \\
\text { in the sample } \%\end{array}$ & $\begin{array}{c}\text { compressive strength } \\
\text { values (MPa) }\end{array}$ \\
\hline $10 \%$ & 115 \\
\hline $20 \%$ & 124 \\
\hline $30 \%$ & 130 \\
\hline
\end{tabular}

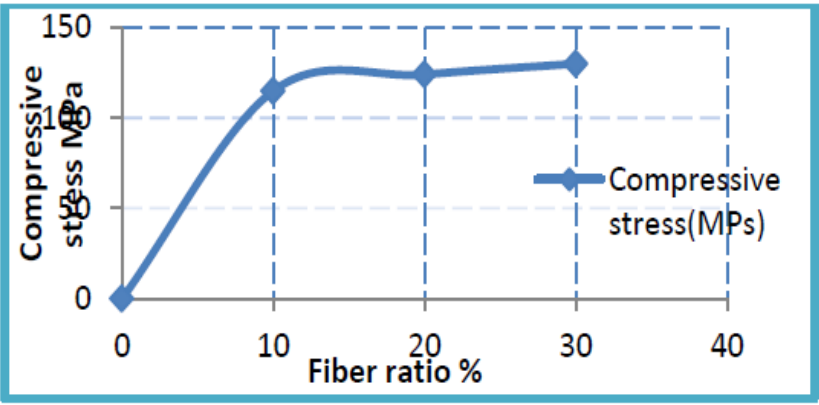

Figure 6: Shows the compressive stress and the ratios of fiber glass used 
ISSN (online): 2581-3048

Volume 6, Issue 1, pp 132-137, January-2022

https://doi.org/10.47001/IRJIET/2022.601023

\subsection{Tensile test results}

Resins are considered fragile materials as their tensile resistance is very low, but when adding glass powder by $10 \%$, $20 \%, 30 \%$, we notice a slight improvement in the tensile strength of the composite material by $10 \%$ higher than the rest of the ratios because the glass is fragile and when the glass ratios increase more than $10 \%$ we notice a decrease in mechanical properties, which leads to a weakening of the bonding forces in the composite material [6], and we notice an improvement in mechanical properties at the rate of $10 \%$ as the highest stress at the value of $40 \mathrm{MPa}$ and when strain value (0.0694) This indicates an improvement in the mechanical properties of the sample of high stress and better ductility compared to the rest of the ratios, and Table (3) shows the values of stress and strain and the figure (7) shows the path of stress and strain for all ratios used, and the value of the modulus of elasticity for pure polyester $(544,537 \mathrm{Mpa})$ and for the material Composite by $10 \%(839.73 \mathrm{Mpa})$ and for composite by $20 \%$ (552.14 Mpa), and by composite by $30 \%$ (251.88 Mpa), which indicates that the elasticity of the composite material is $10 \%$ more, which makes it more tolerant to the effect of pressure and tension compared to the rest of the ratios.

Whereas: $\mathrm{E}$ is the modulus of elasticity in $\mathrm{MPa}$, the quotient of stress is divided by strain change.[9]

Table 3: Shows the results of stress and strain of the highest stress strain value of the composite material to the tension test of the ratios of glass powder used

\begin{tabular}{|l|c|c|c|c|}
\hline & pure & $10 \%$ & $20 \%$ & $30 \%$ \\
\hline $\begin{array}{l}\text { Tensile } \\
\text { stress }(\mathrm{MPa})\end{array}$ & 39 & 40 & 34 & 28 \\
\hline strain & 0.0555 & 0.0694 & 0.0634 & 0.0575 \\
\hline
\end{tabular}

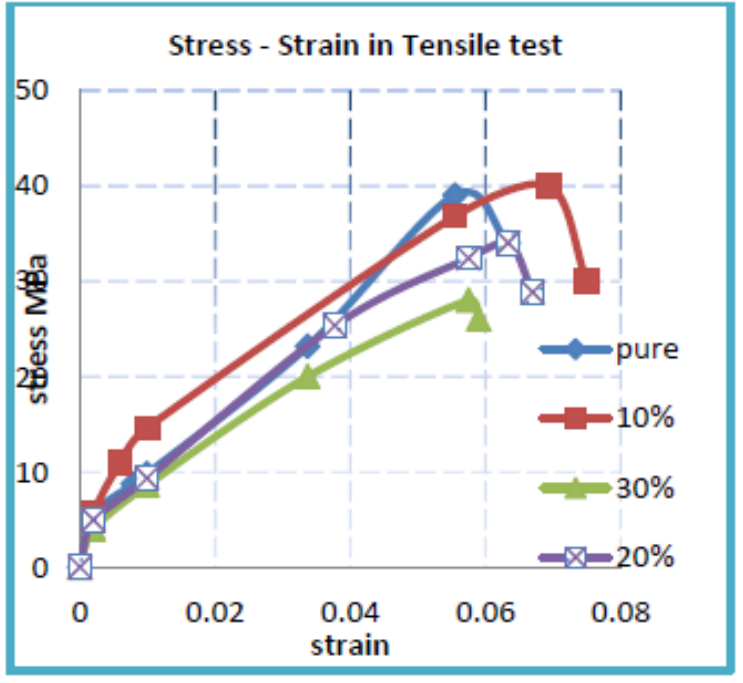

Figure 7: Shows the stress and strain curve of the polymeric compound: for pure polyester, $10 \%, 20 \%, 30 \%$
Table 4: Shows the results of stresses of the highest stress value of the composite material to the tension test of the ratios of fiber glass used

\begin{tabular}{|c|c|}
\hline $\begin{array}{c}\text { The percentage of fiber } \\
\text { in the sample\% }\end{array}$ & $\begin{array}{c}\text { Tensile strength values } \\
\text { (MPa) }\end{array}$ \\
\hline $10 \%$ & 61.3 \\
\hline $20 \%$ & 98.5 \\
$30 \%$ & 153.7 \\
\hline
\end{tabular}

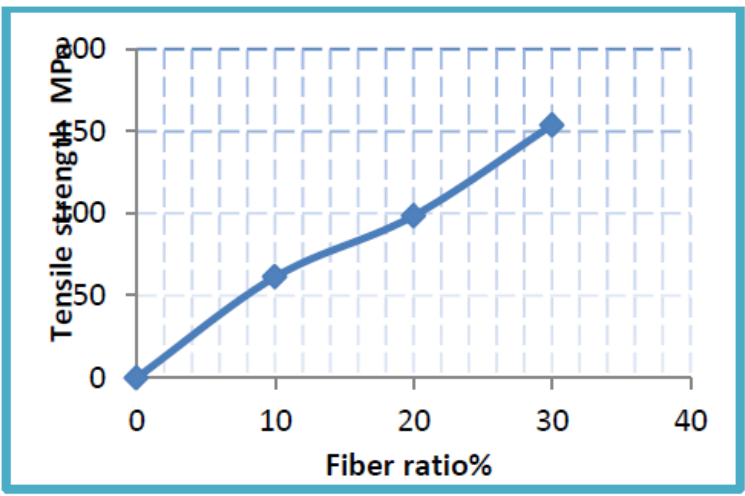

Figure 8: Shows the tensile stress and the ratios of fiberglass used

We note from the study of the figure (8) and from the table (4) that the tensile strength increases significantly with increasing weight ratios of fibers, and this result can be explained by that when the weight ratio of fibers is small the composite material is weak, but when the weight ratios of the fibers increase the composite material becomes strong, and the sample behaves like a fiberglass with resistance The highest tensile strength at these proportions.

\subsection{Results of hardness tests}

Hardness is a measure of the material's resistance to the plastic deformation that occurs in the material under external influence. The hardness was tested using a Shore-D type (Shore Durometer) device. The hardness of the polymeric materials is a device that is like a compass and contains a needle in the middle. hardness is to be measured through to insert the needle into the surface of the material and for a waiting period of about three seconds after which the hardness value is taken from the device, and at least six readings were taken in different places from the sample surface of the unsaturated polyester after strengthening in particles ratio for each case to obtain High accuracy of results and Figure No. (9) It shows the effect of increasing the weight fracture of the added particles on the hardness values, as it is clear that the hardness for the unsaturated polyester material increase with the addition of glass particles at the rate of $10 \%$, but the increase in hardness is less with the increase in the $20 \%$ and $30 \%$ weight fracture, as shown in Table No. (5), And that the particles overlap have similar uniform properties in all directions [8], and these themselves can be of great benefit in some applications that require similar uniform properties, as 
the particles work to increase the resistance of the material to deformation depending on how the particles are distributed within the base material as well as its participation in The stresses borne to calculate the hardness of the composite material together with the base material, may be due to the fact that the particles themselves have high durability and hardness, which in turn leads to an increase in the hardness of the overlapping material, and since the glass is the additive material with a high hardness.

Table 5: Shows the highest hardness of the polymeric composite for the proportions of the glass powder

\begin{tabular}{|l|l|l|l|}
\hline pure & $\mathbf{1 0 \%}$ & $\mathbf{2 0 \%}$ & $\mathbf{3 0 \%}$ \\
\hline $\mathbf{9 1 . 5}$ & $\mathbf{9 9 . 8}$ & $\mathbf{9 6 . 4 7}$ & $\mathbf{9 4 . 5}$ \\
\hline
\end{tabular}

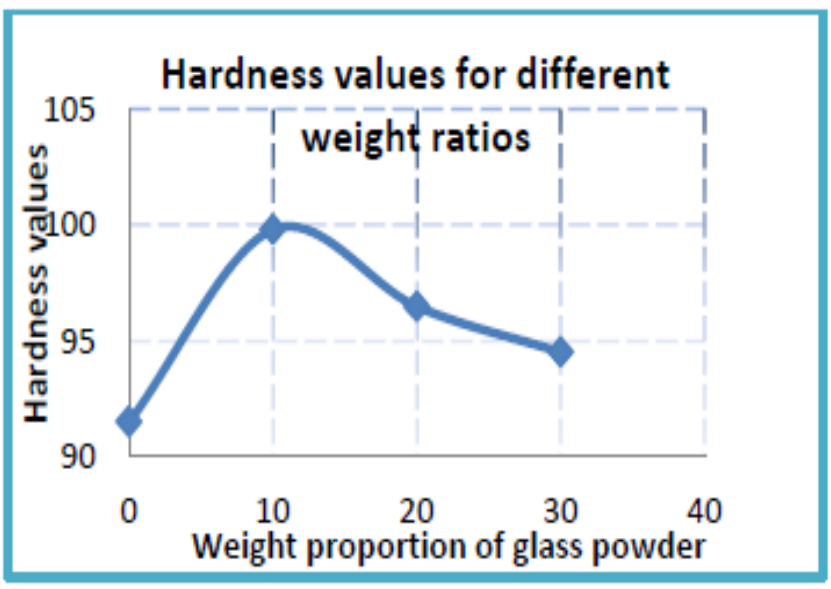

Figure 9: The hardness values of the composite material are pure polyester, $10 \%, 20 \%$ and $30 \%$ of the composite material

The results of the hardness test shown in Figure (10) and in Table (6) show an increase in the hardness values with the increase in the weight ratios of the glass fibers, and the reason for this is that the glass is a ceramic material that gives hardness to the bonding material polyester, which is the result of the bonding of glass fibers and polymeric chains, and this It increases the penetration resistance of the composite material and thus increases its hardness at these proportions

Table 6: Shows the highest hardness of the polymeric composite for the proportions of the fiberglass

\begin{tabular}{|c|c|}
\hline $\begin{array}{c}\text { The percentage of fiber in the } \\
\text { sample\% } \\
10 \%\end{array}$ & Hardness values \\
\hline $20 \%$ & 105 \\
\hline $30 \%$ & 120 \\
\hline
\end{tabular}

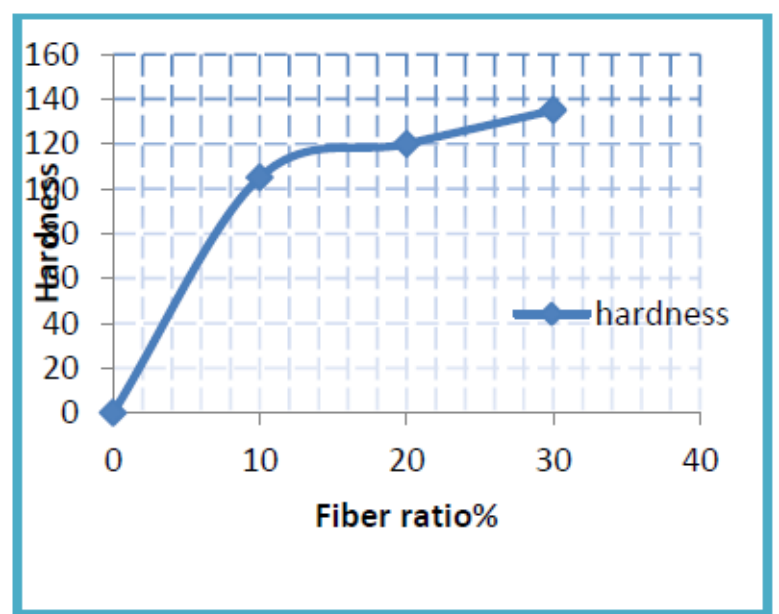

Figure 10: The hardness values of the composite material $10 \%, 20 \%$ and $30 \%$ of the fiber glass

\section{CONCLUSIONS}

The conclusions that can be drawn from this study are:

\subsection{Compression Test}

We notice an improvement in mechanical properties by $10 \%$ when exposed to compressive forces, which leads to elastic deformation resulting from the force until it reaches the highest compressive pressure (104 $\mathrm{MPa})$ and at strain (0.0733), and then until the sample reaches a state of fracture at the compressive pressure $(32.8 \mathrm{MPa}) \mathrm{Pa}$ ) upon strain $(0.11)$ compared to increasing the percentage of glass powder to $20 \%$ and $30 \%$. We observe the opposite results when increasing the proportion of glass powder. Polyester is a brittle material, and an increase in the percentage of glass powder is an increase in the brittleness of the compound, which leads to a decrease in its mechanical properties by increasing the proportions.

The reinforcement of resinous materials with fibers leads to high compression resistance values for the composite material resulting from this reinforcement ratio increase, which represents compression resistance, as the compression resistance rises sharply when reinforcing with glass fibers due to the distribution of the load on the fibers as well as the efficiency of the bindbetween the base material and the reinforcing fibers, which raises resistance values Compression.

\subsection{Tensile Test}

We notice a slight improvement in the tensile strength of the composite material by $10 \%$ than the rest of the percentages of glass powder because glass is a brittle substance and when the percentage of glass increases by more than $10 \%$, we notice a decrease in the mechanical properties when the percentage of glass powder increases, and on the contrary, the tensile 
ISSN (online): 2581-3048

Volume 6, Issue 1, pp 132-137, January-2022

https://doi.org/10.47001/IRJIET/2022.601023

strength of the composite material increases with an increase The percentage of glass fiber as a strengthening element is up to $30 \%$, compared to an increase in the percentage of glass powder, which decreases by $30 \%$.

\subsection{Hardness Test}

The hardness values of unsaturated polyester increase with the addition of glass powder by $10 \%$, but the increase in hardness is less with the increase in the weight of the glass powder, as the particles increase the resistance of the material to deformation depending on how the particles inside the base material are distributed, but the hardness of the composite material increases with the increase in the percentage of the fibers Glass as a strengthening element compared to an increase in the percentage of glass powder, as the increase in the hardness resistance with the increase in the percentage of glass fiber as a strengthening element greater than the increase in the glass powder.

5.4 The best mechanical properties can be obtained when using $30 \%$ glass fibers as opposite to glass powder, as mechanical properties decrease when increasing the percentage of glass powder at $30 \%$.

5.5 We recommend the use of composites made of unsaturated polyester reinforced with glass fibers in the industry more than the use of glass powder of random sizes because of their high mechanical and physical properties.

\section{REFERENCES}

[1] Engineer Aseel Mahmoud Abdullah (teacher), Eng. Ahmed Mudhafar Hashem (teacher assistant), Engineer Ammar Jabbar Badr (teacher assistant), (2011), "The effect of adding alumina particles on the mechanical properties of the compound material that is based on unsaturated polyester fiber reinforced with noncontinuous glass fibers" Al-Qadisiyah Journal of Engineering Sciences, Volume 4, No. 1.
[2] Dr. Maysa Shash (teacher), (2015), “A study of some mechanical properties of a polyunsaturated polyester reinforced material with random glass fibers", Al-Baath University Journal - Volume- 73 - No. 10.

[3] Dr. Abbas Aliwi Al-Jubouri, (2009), "Difference in the ratio of reinforcement with fibers and their effect on the mechanical properties of thermosetting resins", AlQadisiya Journal of Engineering Sciences, Special Issue.

[4] Ali Hassan Resan, (2017), "The Impact of Ultraviolet (UV) Radiation on the Resilience Factor Values of Hybrid Fibro-Polyester Compounds", JOURNAL OF KUFA - PHYSICS, Vol.9, No. 1.

[5] M. Amal Sadiq Ata, M. Nawras Jabbar Nasser, Eng. Ikhlas Ahmed Abdel-Razzaq, (2015), "A study of the effect of adding different fibers to the polyester overlay on the adhesion wear feature", Al-Qadisiyah Journal of Engineering Sciences, Volume 8, Issue 1.

[6] Faeq Hammad Antar, Hind Salah Hasan, (2014), "A study of the mechanical properties of unsaturated polyester resin reinforced with glass fibers," Anbar University Journal of Pure Sciences, Volume VIII, Second Edition.

[7] Adel Subhi Matouk, (2014), "Study of some mechanical properties of polyester fiber reinforced composites intermittent glass fibers and minutes $\mathrm{Al} 2 \mathrm{O} 3, \mathrm{Mg}(\mathrm{OH}) 2$, SiC", Anbar University Journal of Pure Sciences. Volume Eight, Third Issue of the Year.

[8] Dr. Abbas Al-Jibouri, Ali Ibrahim Al-Musawi, Sajid Abdul-Khader Abdullah, (2015) "The effect of the fiber reinforcement ratio on the thermal and mechanical properties of a compound material," Iraqi Journal of Mechanical and Metal Engineering, “, Special Issue (A).

[9] Ghaidaa Ibraheem Ai-Sarraj, Suha Hashim Ahmed, (2020), "Effect of Natural and Industrial Fibers Reinforcement on Mechanical properties Polymeric Matrix Composite", International journal of Advanced Science and Technology, Vol.29, No.1.

\section{Citation of this Article:}

Suha Hashim Ahmed, Ghaidaa Ibrahim Husain, “A Comparative Study of the Experimental Results of Mechanical Tests of Composite Material Made of Polyester-Reinforced Fiber and Glass Powder" Published in International Research Journal of Innovations in Engineering and Technology - IRJIET, Volume 6, Issue 1, pp 132-137, January 2022. Article DOI https://doi.org/10.47001/IRJIET/2022.601023 